\title{
Coordination at the 10-year mark of the JHLSCM-from global response to local preparedness
}

\author{
Marianne Jahre \\ Department of Industrial Management and Logistics, Lund University, \\ Lund, Sweden and \\ Department of Accounting and Operations Management, \\ BI Norwegian Business School, Oslo, Norway, and \\ Leif-Magnus Jensen \\ Supply Chain and Operations Management, \\ School of Engineering at Jönköping University, Jönköping, Sweden
}

\begin{abstract}
Purpose - At the inception of the Journal of Humanitarian Logistics and Supply Chain Management (JHLSCM), logistics coordination was identified as important, both in practice and research, but few studies on the topic had been published. Ten years later, many, if not most, papers in the journal mention the topic. So the picture has changed, but to what extent? This paper discusses how coordination research has followed humanitarian logistics practice and vice versa.

Design/methodology/approach - The point of departure in the present article is the most salient topic from the study's original papers (Jahre et al., 2009; Jahre and Jensen, 2010). The authors discuss how these topics have developed in research and practice. A recent literature review (Grange et al., 2020) enables us to pick relevant papers from JHLSCM and supplement them with more recent ones. The authors complement this approach with updated data on the cluster system, particularly the logistics cluster, to add insights from the empirical domain.

Findings - In practice, the cluster concept has developed from coordination within clusters in response to the inclusion of inter-cluster coordination in preparedness, and more recently a focus on localized preparedness. However, JHLSCM research does not appear to have kept pace, with a few notable exceptions. The majority of its papers still focus on response. To the extent that preparedness is covered, it is primarily done so at the global level.

Originality/value - The authors use a framework to discuss humanitarian logistics coordination research and identify important gaps. Based on developments in practice, the study's key contribution is a revised model with suggestions for further research.
\end{abstract}

Keywords Coordination, Cluster system, Conceptual, Research agenda

Paper type Research paper

\section{Introduction}

Coordination has been and continues to be one of the mainstay topics in humanitarian logistics. The Journal of Humanitarian Logistics and Supply Chain Management (JHLSCM) is a good example of this popularity. Out of approximately 200 articles published since the inception of the journal, a simple search on the word "coordination" yields 163 results, although the main contribution of each article might not relate directly to coordination. In this

(C) Marianne Jahre and Leif-Magnus Jensen. Published by Emerald Publishing Limited. This article is published under the Creative Commons Attribution (CC BY 4.0) licence. Anyone may reproduce, distribute, translate and create derivative works of this article (for both commercial and non-commercial purposes), subject to full attribution to the original publication and authors. The full terms of this licence may be seen at http://creativecommons.org/licences/by/4.0/legalcode

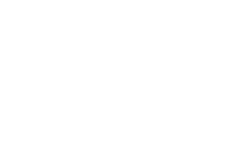


JHLSCM 11,4 sense, we might say that coordination in humanitarian logistics, at least at a surface level, is now a well-established and mature topic.

This was not the case at the journal's inception. When we published articles on theoretical development and cluster coordination 10 years ago (Jahre et al., 2009; Jahre and Jensen, 2010), the specific research in the field was limited and there was a great need for new and suitable frameworks, as well as empirical research. Ten years later, the picture has changed, but how much?

The purpose of this paper is to discuss how the research on coordination has followed the practice in humanitarian logistics or vice versa. To this end, we use the development of the cluster system as our empirical case to show which research issues still need more attention. Particularly, we cover two important dimensions: preparedness versus response and to what extent focus has been on the global versus the local level.

Our point of departure is the most salient topics from the original papers and how these topics have developed in research and practice. A recent literature review on coordination already exists (Grange et al., 2020), enabling us to relatively easy pick relevant papers and supplement them with more recent ones. We complement this with updated empirical material on the cluster system, particularly the logistics cluster, to add insights from the empirical domain. Our ambition and approach are conceptual in nature, allowing us to comment on remaining gaps and future directions.

\section{Clusters in practice}

Targeting logistics specifically for coordination started with the United Nations Joint Logistics Centre (UNJLC), which was employed specifically to coordinate logistics issues in humanitarian relief operations and institutionalized by the UN in 2002. The UNJLC was gradually superseded by the cluster system from 2005 onwards and in 2008 it was formally merged into the Logistics Cluster. Clusters were introduced to improve efficiency in the five following key areas (OCHA, 2007):

(1) Sufficient global capacity to meet current and future emergencies

(2) Predictable leadership at a global and local level

(3) Strengthened partnerships between UN bodies, non-governmental organizations (NGOs) and local authorities

(4) Accountability, both for the response and vis-à-vis beneficiaries

(5) Strategic field-level coordination and prioritization

Its first application occurred when nine clusters were established within $24 \mathrm{~h}$ of the 2005 earthquake in Pakistan. Since then, two evaluations of the approach have taken place (Stoddards et al., 2007; Steets et al., 2010). Based on this, the IASC Transformative Agenda was established (IASC, 2012).

Originally termed the Logistics Cluster Cell, the focus of the logistics coordination effort was on operational support once disasters had occurred. Following the Logistics Cluster evaluation (Majewski et al., 2012), its strategic plan 2013-2015 was developed (GLC, 2013). The attention was still on operational support in response, although preparedness was arriving on the agenda. However, local preparedness was considered to be beyond their capacity: "The ability of the Logistics Cluster to conduct operations, participate in targeted preparedness actions, or engage with partners at the global level to formulate consensus is restricted by: (1) The obligation to respond in a timely way to unpredictable new, as well as on-going emergencies; (2) The availability of funding; (3) The size, composition, and expertise of the Logistics Cluster Cells." The key was to "Ensure that the regular activities of the Global 
Logistics Cluster Support Cell are continued, including maintaining field support and existing levels of deployment capacity; maintaining engagement with partners at the global level in terms of coordination and training; and supporting limited preparedness initiatives at current levels."

A footnote shows the discussions on developing local preparedness at the time, stating that "Some stakeholders question whether the GLC has a mandate for building national preparedness capacities, however, the November 2006 IASC Guidance Note on Using the Cluster Approach to Strengthen Humanitarian Response states, 'Where appropriate, sector leads should promote training and capacity-building initiatives, particularly in terms of strengthening the capacity of local authorities to provide leadership.' This recommendation should lead to a clearer definition of where and when it is appropriate for the GLC to provide such national preparedness assistance and what this entails" (Logistics Cluster Strategic Plan, 2012-2015 in GLC, 2013, p. 12).

The original cluster approach was about coordination between organizations within the specific sectors; for example, water and sanitation organizations in the Water Sanitation and Hygiene cluster. However, it soon became evident that coordination between the clusters was lacking: "A more fundamental barrier to addressing cross-cutting issues stems from weak inter-cluster coordination, including inadequate information management and analysis" (Stoddard et al., 2007, p. 40). Eventually, inter-cluster coordination came onto the agenda: "Guided by the Humanitarian Country Team (HCT), inter-cluster coordination provides a platform for clusters to work together to advance the delivery of assistance to affected people effectively and efficiently. It does this by encouraging synergies between sectors, ensuring roles and responsibilities are clearly defined, closing potential gaps, and eliminating duplication" (IASC, 2015).

At the same time as the focus on inter-cluster coordination was increasing, preparedness was climbing up the agenda through a new logistics cluster strategy. The original version (GLC, 2016-2018) made no mention of localization, but did state that it is important to "Create awareness on the importance of logistics preparedness and on the Logistics Cluster role in emergencies" (p. 7). The term localization was not used until the Field Based Preparedness Project ("the Project") came into being in 2020 (FBPP, 2020a-i): "The objective is to catalyse the strengthening and localisation of national humanitarian logistics by empowering national responders and promoting partnerships and long-term collaborative approaches. Where an active IASC Logistics Cluster operation is present, upon its deactivation the Project might be initiated as a means to transition into preparedness and capacity strengthening. This leverages momentum relationships and established coordination platforms across the response community and allows identified logistics response gaps and bottlenecks to be addressed in a sustainable manner". Preparedness projects are now ongoing in Bangladesh, Cambodia, Colombia, Haiti, Iraq, the Lao People's Democratic Republic, Madagascar, Malawi, Mozambique, the Pacific Region, the Philippines, Sierra Leone and Zimbabwe (https:// $\log$ cluster.org/).

To summarize, Figure 1 provides an overview of the key phases in the cluster development, focusing on the logistics cluster.

To conclude this section, we see that the concept (GLC, 2020) has developed from coordination within clusters in response to also include inter-cluster coordination in preparedness, and more recently a focus on localized preparedness. It will be interesting to see how this will be formulated in the strategy going forward. Our question, then, is how has humanitarian logistics research followed up this change in practice?

\section{The state of the theory}

The literature review encompasses two areas: humanitarian logistics coordination in terms of the main streams with relevance to our starting point and the clusters themselves. 


\section{JHLSCM 11,4}

\section{8}

Figure 1.

Development of the cluster concept

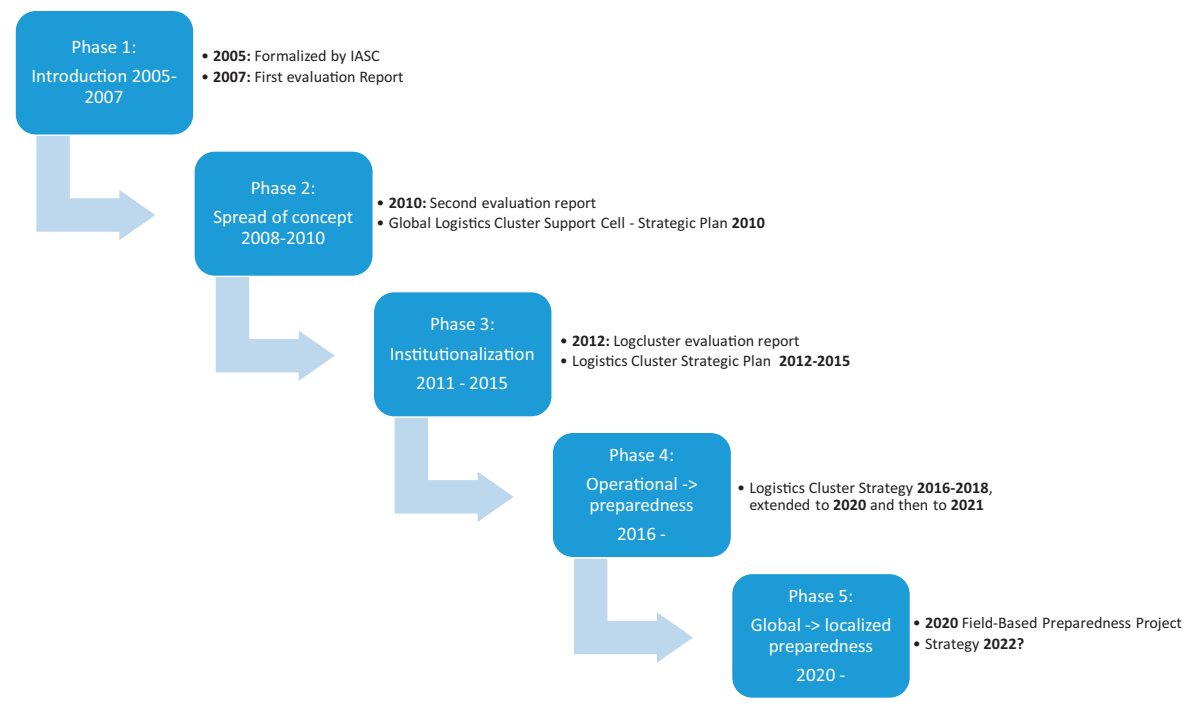

\subsection{Coordination in humanitarian logistics}

The importance of coordination seemed clear from the start. However, there were challenges in using the term among practitioners, and other terms such as collaboration and cooperation were used interchangeably (Jensen, 2012; Bealt et al., 2016).

At the time of the two studies, just over a decade ago (Jahre et al., 2009; Jahre and Jensen, 2010), the literature on coordination in humanitarian logistics was very limited. This meant that a logical starting point was to approach actors in the field to inductively identify and explore the most pressing coordination-related issues. This led us to review the literature on supply chain coordination in general and to a first line of thinking on relevant theory. Jahre et al. (2009) suggested that three important dimensions were permanent and temporary networks, decentralization, centralization and-notably-horizontal and vertical coordination. Jahre and Jensen (2010) drew on this thinking and suggested important dimensions to be vertical (or pipeline) and horizontal coordination, both within (functional) and among the clusters. A major point in the early work was that strong attention to the functional coordination could come at the cost of weaker coordination among the clusters and that mechanisms must be found to improve this. In terms of the vertical dimension, emphasis was placed on the need to coordinate the supply chain from one response to the next, dealing with the entire affected region.

Considering the subsequent literature, three areas can be identified-operational coordination, preparedness and localization-can be identified, with a rough temporal dependence.

The operational area corresponds to coordination issues in the response operation itself. Typical issues, such as which organizations carry out what activities and where, must be solved in any operation. The large number of involved organizations and inherent features of the context such as uncertain needs and damage to infrastructure, exacerbates the coordination challenges. Early solution mechanisms such as the UNJLC picked some of the most essential coordination tasks and assigned them to ad hoc groups based on improvised 
resources (Jahre et al., 2009). Subsequently, and partially with the clusters, the attention Coordination at moved on to lead organizations with a clear responsibility.

Alternative approaches were also suggested, such as the use of Logistics Service Provider (LSP) to take over significant coordination tasks in humanitarian logistics, perhaps best represented through the idea of a 4PL (Abidi et al., 2015; Jensen, 2012; Vega and Roussat, 2015). Some authors found potential for outsourcing tasks in humanitarian logistics to LSPs in general, but also considerable skepticism, especially for tasks that would imply more control for the LSP (Bealt et al., 2016; Gossler et al., 2019). Others suggested that the role for commercial actors should be considered in a broader sense (Kaneberg, 2018; Medel et al., 2020), while some focused more on the specifics of the coordinators themselves (Akhtar et al., 2012). Finally, the idea of choreography has been presented as a more decentralized solution where organizations adapt more dynamically to each other using contemporary information technology (IT) tools and common understanding in a community of learning context (Grange et al., 2020; Mutebi et al., 2020).

The preparedness area deals with the time before or between operations. The overall challenge is that a dollar spent in preparation saves several dollars in an actual operation, but funding is often a challenge (Jahre et al., 2016; Lewin et al., 2018). Several approaches have been suggested for preparedness. One is to conceptualize preparedness in terms of resilience (e.g. L'Hermitte et al., 2016). Jahre (2017) considered preparedness in terms of supply chain risk and showed at least ten different risk strategies in empirical studies within humanitarian logistics. These form a subset of the strategies seen in the supply chain risk management literature. Notably, risk strategies that focus on holding strategic stock can be costly and better approaches might involve increased flexibility. Prepositioning of stock can be carried out in the context of postponement where supplies are not necessarily labeled until they are needed (e.g. Jahre and Heigh, 2008), creating a baseline of coordination for the humanitarian organizations as a whole. Indeed, prepositioning has received considerable attention, with more well-developed quantitative decision support systems (e.g. Di Pasquale et al., 2020).

Another approach is exemplified by Jensen and Hertz (2016), who suggested developing clearer roles for actors such as NGOs to reduce the need for coordination during the response itself. If actors have already defined what they can provide and how they will act during the response, it reduces the need for extensive coordination once the response becomes a reality.

Finally, the area of localization has come under more scrutiny but with little research so far. Whereas global prepositioning refers to the placement of stocks, localization deals with involving local actors in the response, or leaving it to them to lead, and supports them in developing their own logistics preparedness. Since such local actors have superior local knowledge and potentially better contact with actual needs, the benefits seem obvious but the topic has been intractable. Indeed, Frennesson et al. (2020) found quite different attitudes to the development of more localization in humanitarian logistics, from decentralization, partial transfer, full transfer to continued centralization representing the status quo. Although most respondents in the study were positive about decentralization and transferring activities to local actors, more extensive implementation of this thinking remains. Wood and Frazier (2020) addressed the underlying models of aid provision in terms of centralization and decentralization (that is, localization), but this thinking has yet to be more developed in terms of supply chain coordination.

We should note that the separation into three areas is, to some extent, a device of convenience; for example, a lead organization can play an important role both in preparedness and operations, as is seen in the case of the logistics cluster, and an LSP could play different roles at several points in a response (see, e.g. Falagara Sigala and Wakolbinger, 2019). There are many examples of deeper exploration of how to coordinate such detailed issues as air traffic control (Veatch and Goentzel, 2018) or volunteer 
JHLSCM 11,4 assignments (Garcia et al., 2018). Here, however, we retain the focus on what to coordinate and, to a certain extent, on what actors are involved.

\subsection{Clusters in academic research}

In their editorial when JHLSCM was launched, Kovács and Spens (2011) stated: "A striking feature of humanitarian logistics is the focus on co-opetition. Efforts are joined in practice in the establishment of purchasing consortia, joint hubs, clusters, and communities of practice in logistics" (p. 9; emphasis added).

Given that humanitarian logistics has generally focused on coordination, and particularly in JHLSCM, one would expect a key coordination mechanism such as the cluster to receive significant attention from researchers. However, while we identified 113 papers when searching for "cluster" in JHLSCM, there are surprisingly few empirical studies. We identified 14 notable exceptions (Table A1). The remaining 99 papers either use or refer to clustering as part of their research techniques; refer to a few information sources from the clusters; refer to or use information from/on other types of clusters; refer to papers in the table, for example when discussing coordination, but without going into the cluster concept; or refer to clustering of logistics activities, such as vehicles or warehouses, but not the cluster concept itself. Finally, the few papers that discuss or mention the cluster as part of the humanitarian system do so in connection with coordinating response, not preparedness. The last column in Table A1 lists relevant findings on the two key dimensions we have looked at: preparedness versus response and global versus local level.

Based on Table A1, we can conclude the following. One paper focuses on preparedness, while most of the others focus on response with some on both. Among the papers on preparedness, two discuss local as well as global capacity, the remaining focus on the global level. When it comes to research approach, most papers are literature reviews and/or conceptual. Empirical papers are based solely on interviews. We found no "mixed-methods" papers, for example, in terms of case studies combined with modeling or other analytical techniques. Other parts of the humanitarian logistics research increasingly use such approaches, partly to provide explanatory and normative evidence and advice to practice.

\section{Concluding discussion, identified gaps and suggested further research}

In a broad sense, the empirical focus on the clusters moving from response to preparedness and lastly localization is matched by the literature. The majority of the papers deal with coordination during the response, and far fewer papers deal with coordination in the preparedness phase. So far, the attention to the issue of localization has only resulted in a couple of papers that deal with coordination. However, it should be noted here that we have focused on papers published in JHLSCM and that localization in terms of local capacity building has been covered substantially in other journals, for example within development and disaster risk reduction (e.g. Hagelsteen et al., 2021; Kuipers et al., 2019).

The 2010 model, as shown in Figure 2, essentially outlined several dimensions and made these more concrete in terms of cluster coordination. Vertical and horizontal coordination remain important and have also been used in more recent work (Grange et al., 2020). However, the model is rather static overall and has some weaknesses. For example, the levels of coordination-operational, tactical and strategic-have some foundation in literature, but do not describe more recent developments such as localization very well. Nor does the model really speak to the phases of an intervention. Although the level of coordination dimension could be developed, here we suggest that the model from Jahre et al. (2009, Fig. 1, p. 3) is more promising in terms of capturing the developments identified in Section 3. This model consisted of three dimensions with two alternatives for each-the network (permanent and 


\begin{tabular}{|c|c|c|c|}
\hline \multicolumn{4}{|c|}{ Type of coordination } \\
\hline & \multicolumn{2}{|c|}{ Horisontal } & \multirow{2}{*}{$\begin{array}{c}\text { Vertical } \\
\text { Among clusters }\end{array}$} \\
\hline & Within cluster & Among clusters & \\
\hline Operational & $\begin{array}{l}\text { Organizations in } \\
\text { a cluster } \\
\text { cooperate in an } \\
\text { operation }\end{array}$ & $\begin{array}{l}\text { Cooperation } \\
\text { among different } \\
\text { clusters in an } \\
\text { operation }\end{array}$ & $\begin{array}{l}\text { Pipeline for an } \\
\text { operation is } \\
\text { coordinated } \\
\text { among } \\
\text { participants }\end{array}$ \\
\hline Tactical & $\begin{array}{l}\text { Organizations in } \\
\text { a cluster } \\
\text { cooperate at the } \\
\text { regional level }\end{array}$ & $\begin{array}{l}\text { Clusters } \\
\text { cooperate at the } \\
\text { regional level for } \\
\text { storage, capacity }\end{array}$ & $\begin{array}{l}\text { Storage and } \\
\text { distribution from } \\
\text { a regional level }\end{array}$ \\
\hline Strategic & $\begin{array}{l}\text { Global capacity } \\
\text { building, } \\
\text { standards for a } \\
\text { cluster }\end{array}$ & $\begin{array}{l}\text { Global } \\
\text { assessments, } \\
\text { inter-cluster } \\
\text { standards }\end{array}$ & $\begin{array}{l}\text { Purchasing, } \\
\text { global stockpiles } \\
\text { and pipelines to } \\
\text { affected regions }\end{array}$ \\
\hline
\end{tabular}

Source(s): Jahre and Jensen (2010, Table 2, p. 668)
Coordination at the 10-year mark

591

Figure 2.

Types of coordination

temporary), coordination (vertical and horizontal) and the structure (central and decentral). An update of the model is timely and we present a suggestion here based on the concepts used in theory and practice and where we have used different marking to show where the humanitarian logistics focus on coordination has been until now.

The coordination dimension can be retained as vertical and horizontal, but the literature has expanded on both dimensions. The horizontal dimension consists of functional or withincluster coordination and inter-cluster coordination (an issue that has received little attention). There is potentially also coordination beyond the clusters with other organizations or coordination bodies working at the same level. The vertical dimension does refer to the pipeline from stocks of emergency replies but should also reflect global humanitarian supply chains all the way to sourcing. In this sense, there is both a distribution pipeline into the affected area but also an inbound pipeline. Depending on how the system is organized and the size of an intervention, this inbound pipeline can be critical, since stocks of emergency supplies seldom meet the needs.

The main weight of research has dealt with functional coordination in terms of the different sectors (or clusters) in the field, as well as the role of the lead organization, whether it is the cluster or another type of organization altogether, such as an LSP. There has been considerably less focus on how to make sectors or clusters work together, and the supply chain management idea of coordinating the vertical supply chain to serve the end customer (or recipient) has not received a great deal of attention. The idea of self-organization (choreography) is relatively new and should also be explored. Finally, the question of "how" to coordinate in terms of what specific mechanisms work well in which context should receive more attention. The use of technology and availability of (big) data will be important in developing new mechanisms, but we suggest that the development should start with the coordination mechanisms rather than the tools.

The second dimension of the model is the network and its permanent and temporary nature in terms of preparedness and response. The preparedness network deals with activities between interventions and is the basis for mobilization and the performance of the network in an actual intervention. While some research has been carried out on preparedness and the issue of coordination, it appears to be fairly limited. Some literature points to the 
JHLSCM 11,4

\section{2}

importance of involving actors in the planning stage to involve them in the actual response, and the idea of capacity building is important for strengthening response. The idea of developing clearer roles to build preparedness at a more conceptual level has been raised. The area of prepositioning is strongly related to thinking around preparedness, and the idea of moving stock to good locations ahead of time is appealing. However, as seen in Section 3, prepositioning is not always the answer and can add costs to the supply chain. Furthermore, preparedness can also be about building in supply chain flexibility, an issue that deserves more attention. Costs of building higher inventory should be contrasted with the cost of building in more flexibility or faster supply chains, and this type of issue could be addressed with more model-building approaches. It would also combine well conceptually with recent work within resilience.

Finally, the structure dimension, which originally consisted of centralization and decentralization, lent itself to considering, for example, the placement of regional depots as a form of decentralization. At the same time, elements of the cluster system did centralize some important tasks globally to develop common standards and operating procedures within the humanitarian community. These developments were dominated by the larger international organizations. The more recent discussion concerns a type of localization, which involves and strengthens local actors to a different degree. In fact, Frennesson et al. (2020) excluded decentralization as a form of localization, keeping the latter for transfer of capacities from international organizations to local actors outside of their own country office. Hence, the revised model in Figure 3 uses the terms globalized and localized instead of centralized versus decentralized. While much of the aid system is still quite globalized, the ongoing change toward localization (Wood and Frazier, 2020) would have major implications for coordination practice and future research. Consequently, a broad range of research topics on localization remain, particularly empirical research on the involvement of local resources. We suggest that both case studies and mixed method research study coordination mechanisms and their performance. It is still an open question as to what such coordination and involvement would look like when working well, and the consequences for the intervention overall.

Figure 3.

Three dimensions as basis for development

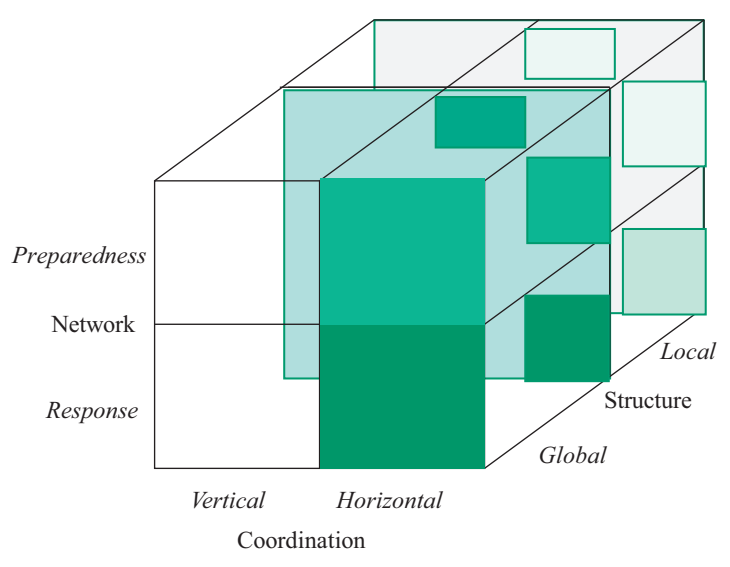

Source(s): Adapted from Jahre et al. (2009) 
A notable point in terms of the framework is that the network is described in terms of preparedness and response, and the structure dimension in terms of the local and global. At the same time, the structure dimension deals with relationships and processes. We suggest that the Industrial Marketing and Purchasing (IMP) literature (Håkansson and Snehota, 1995, 2006) and its ARA model describing actors, resources and activities, including their connections, might be a promising way to expand the understanding of the structure dimension.

Expanding on and classifying the research gaps, we can formulate general questions that follow the updated dimensions of the model, as an additional guide to develop more specific research.

Table 1 focuses on horizontal coordination both within and between clusters and organizations, while Table 2 shows the combinations of vertical-along the supply chaincoordination with local and global.

These two tables represent a selection of what we find are salient questions in the current setting. The most pertinent questions are seen to change over time, resulting both from the research that is done and because of the changing nature of humanitarian logistics. As such, we suggest the updated model should be considered as a framework to guide research on coordination rather than a static list of topics. We should also note that the nature of the research needs to be broadened to include more mixed-method research and more quantitative approaches. There is a general lack of empirically based studies, and the existing studies that are empirically based typically stick to case studies and interviews.

Overall, we can say that the research on coordination in humanitarian logistics has followed some of the main developments, as seen in the practice. However, we cannot say much about how research and practice build on each other based on the study we have undertaken. This could also point in the direction of more longitudinal studies to see how concepts are introduced and adapted in the field. Due to our focus on JHLSCM publications, our study only represents a limited part of ongoing humanitarian logistics research. Through this paper, perhaps we can challenge others in our research community to extend this review by including other journals and expand on the dimensions included in the model.

\begin{tabular}{lll}
\hline & Localized & Globalized \\
\hline Preparedness & $\begin{array}{l}\text { How can preparedness be anchored so that } \\
\text { organizations cooperate locally? }\end{array}$ & $\begin{array}{l}\text { How can global standards and capacity be } \\
\text { built while involving a broad base of actors? }\end{array}$ \\
Response & $\begin{array}{l}\text { How can local resources be both involved and } \\
\text { used in an intervention (especially early on)? }\end{array}$ & $\begin{array}{l}\text { How are the organizations in an operation } \\
\text { supported by global resources? }\end{array}$ \\
& &
\end{tabular}

Table 1.

Horizontal coordination vs network and structure

\begin{tabular}{lll}
\hline & Localization & Globalized \\
\hline Preparedness & $\begin{array}{l}\text { How can supply chains connect better to } \\
\text { reinforce local resources when needed? }\end{array}$ & $\begin{array}{l}\text { How can global supply chains be made } \\
\text { flexible enough to connect to where they } \\
\text { are needed? }\end{array}$ \\
Response & $\begin{array}{l}\text { How can the local resources be used to define the } \\
\text { needs to ensure the full requirements of } \\
\text { recipients are covered? }\end{array}$ & $\begin{array}{l}\text { How should global supply chains be } \\
\text { managed in an intervention? }\end{array}$
\end{tabular}

Table 2 .

Vertical coordination vs network and structure 
JHLSCM 11,4

594

\section{References}

Abidi, H., de Leeuw, S. and Klumpp, M. (2015), "The value of fourth-party logistics services in the humanitarian supply chain", Journal of Humanitarian Logistics and Supply Chain Management, Vol. 5 No. 1, pp. 35-60.

Akhtar, P., Marr, N.E. and Garnevska, E.V. (2012), "Coordination in humanitarian relief chains: chain coordinators", Journal of Humanitarian Logistics and Supply Chain Management, Vol. 2 No. 1, pp. 85-103.

Alp Ertem, M. and Buyurgan, N. (2011), “An auction-based framework for resource allocation in disaster relief", Journal of Humanitarian Logistics and Supply Chain Management, Vol. 1 No. 2, pp. 170-188.

Apte, A. (2020), "Understanding readiness metrics for the humanitarian operations through literature review", Journal of Humanitarian Logistics and Supply Chain Management, Vol. 10 No. 3, pp. 321-345.

Battini, D., Peretti, U., Persona, A. and Sgarbossa, F. (2014), “Application of humanitarian last mile distribution model", Journal of Humanitarian Logistics and Supply Chain Management, Vol. 4 No. 1, pp. 131-148.

Bealt, J., Fernández Barrera, J.C. and Mansouri, S.A. (2016), "Collaborative relationships between logistics service providers and humanitarian organizations during disaster relief operations", Journal of Humanitarian Logistics and Supply Chain Management, Vol. 6 No. 2, pp. 118-144.

Di Pasquale, V., Fruggiero, F. and Iannone, R. (2020), "A numerical approach for inventory prepositioning in emergency management", Journal of Humanitarian Logistics and Supply Chain Management, Vol. 10 No. 2, pp. 205-230.

Falagara Sigala, I. and Wakolbinger, T. (2019), "Outsourcing of humanitarian logistics to commercial logistics service providers", Journal of Humanitarian Logistics and Supply Chain Management, Vol. 9 No. 1, pp. 47-69.

FBPP (2020a), Logistics Cluster Field-Based Preparedness Project: Project Concept Note, Dec. 2020, available at: https://logcluster.org/ (accessed 27 May 2021).

FBPP (2020b), Logistics Cluster Field-Based Preparedness Project: Fundamentals of Institutional Capacity Strengthening, Dec. 2020, available at: https://logcluster.org/ (accessed 27 May 2021).

FBPP (2020c), Logistics Cluster Field-Based Preparedness Project: Phase I: Analysis and Planning, Dec. 2020, available at: https://logcluster.org/ (accessed 27 May 2021).

FBPP (2020d), Logistics Cluster Field-Based Preparedness Project: Phase II: Communications, Policy and Resource Advocacy (CPRA), Dec. 2020, available at: https://ogcluster.org/ (accessed 27 May 2021).

FBPP (2020e), Logistics Cluster Field-Based Preparedness Project: Phase III: Support to Implementation, Dec. 2020, available at: https://ogcluster.org/ (accessed 27 May 2021).

FBPP (2020f), Logistics Cluster Field-Based Preparedness Project: The ICS Framework Overview, Dec. 2020, available at: https://logcluster.org/ (accessed 27 May 2021).

FBPP (2020g), Logistics Cluster Field-Based Preparedness Project: FBPP ICS Theory of Change, Dec. 2020, available at: https://logcluster.org/ (accessed 27 May 2021).

FBPP (2020h), Logistics Cluster Field-Based Preparedness Project: Entry-Point and Process Milestones Compendium, Dec. 2020, available at: https://logcluster.org/ (accessed 27 May 2021).

FBPP (2020i), Logistics Cluster Field-Based Preparedness Project: Formulating Capacity Outcome Statements (COS), Dec. 2020, available at: https://logcluster.org/ (accessed 27 May 2021).

Frennesson, L., Jahre, M., Kembro, J., de Vries, H. and Van Wassenhove, L. (2020), "Localisation of logistics preparedness in International Humanitarian Organisations", Journal of Humanitarian Logistics and Supply Chain Management, pp. 2042-6747. doi: 10.1108/JHLSCM-06-2020-0048.

Garcia, C., Rabadi, G. and Handy, F. (2018), "Dynamic resource allocation and coordination for highload crisis volunteer management", Journal of Humanitarian Logistics and Supply Chain Management, Vol. 8 No. 4, pp. 533-556. 
Gavidia, J.V. (2017), “A model for enterprise resource planning in emergency humanitarian logistics”, Coordination at Journal of Humanitarian Logistics and Supply Chain Management, Vol. 7 No. 3, pp. 246-265.

GLC (2013), Logistics Cluster Strategy 2013-2015, available at: https://logcluster.org/ (accessed 27 May 2021).

GLC (2016-2018), Logistics Cluster Strategy 2016-2018, available at: https://logcluster.org/ (accessed 27 May 2021).

GLC (2020), Logistics Cluster Strategy 2016-2021, available at: https://logcluster.org/ (accessed 27 May 2021).

Gossler, T., Falagara Sigala, I., Wakolbinger, T. and Buber, R. (2019), “Applying the Delphi method to determine best practices for outsourcing logistics in disaster relief", Journal of Humanitarian Logistics and Supply Chain Management, Vol. 9 No. 3, pp. 438-474.

Gralla, E., Goentzel, J. and Chomilier, B. (2015), "Case study of a humanitarian logistics simulation exercise and insights for training design", Journal of Humanitarian Logistics and Supply Chain Management, Vol. 5 No. 1, pp. 113-138.

Grange, R., Heaslip, G. and McMullan, C. (2020), "Coordination to choreography: the evolution of humanitarian supply chains", Journal of Humanitarian Logistics and Supply Chain Management, Vol. 10 No. 1, pp. 21-44.

Hagelsteen, M., Becker, P. and Abrahamsson, M. (2021), "Troubling partnerships: perspectives from the receiving end of capacity development", International Journal of Disaster Risk Reduction, Vol. 59, p. 102231.

Håkansson, H. and Snehota, I. (1995), Developing Relationships in Business Networks, Thompson Business Press, London.

Håkansson, H. and Snehota, I. (2006), "No business is an island: the network concept of business strategy”, Scandinavian Journal of Management, Vol. 22 No. 3, pp. 256-270.

Heaslip, G., Kovács, G. and Grant, D.B. (2018), "Servitization as a competitive difference in humanitarian logistics", Journal of Humanitarian Logistics and Supply Chain Management, Vol. 8 No. 4, pp. 497-517.

IASC (2012), Transformative Agenda, available at: https://interagencystandingcommittee.org/iasctransformative-agenda (accessed 1 June 2021).

IASC (2015), IASC Reference Module for Cluster Coordination at Country Level, available at: https:// interagencystandingcommittee.org/iasc-transformative-agenda/iasc-reference-module-clustercoordination-country-level-revised-july-2015 (accessed 1 June 2021).

Jahre, M. (2017), "Supply chain strategies in Humanitarian logistics: a review of how actors Mitigate supply chain risks", Journal of Humanitarian Logistics and Supply Chain Management, Vol. 7 No. 2, pp. 82-101.

Jahre, M. and Heigh, I. (2008), "Does the current constraints in funding promote failure in Humanitarian supply chains?”, Supply Chain Forum: An International Journal, Vol. 9 No. 2, pp. 44-54.

Jahre, M. and Jensen, L.-M. (2010), "Coordination in humanitarian logistics through clusters", International Journal of Physical Distribution and Logistics Management, Vol. 40 Nos 8/9, pp. 657-674.

Jahre, M., Jensen, L.-M. and Listou, T. (2009), "Theory development in humanitarian logistics: a framework and three cases", Management Research News, Vol. 32 No. 11, pp. 1008-1023.

Jahre, M., Pazirandeh, A. and Van Wassenhove, L.N. (2016), "Defining logistics preparedness: a framework and research agenda", Journal of Humanitarian Logistics and Supply Chain Management, Vol. 6 No. 3, pp. 372-398.

Jensen, L.-M. (2012), "Humanitarian cluster leads: lessons from 4PLs", Journal of Humanitarian Logistics and Supply Chain Management, Vol. 2 No. 2, pp. 148-160.

Jensen, L.-M. and Hertz, S. (2016), "The coordination roles of relief organisations in humanitarian logistics", International Journal of Logistics: Research and Applications, Vol. 19 No. 5, pp. 465-485. 
JHLSCM 11,4
Kaneberg, E. (2018), "Managing commercial actors in strategic networks in emergency preparedness", Journal of Humanitarian Logistics and Supply Chain Management, Vol. 8 No. 2, pp. 153-183.

Kovács, G. and Spens, K. (2011), "Humanitarian logistics and supply chain management: the start of a new journal", Journal of Humanitarian Logistics and Supply Chain Management, Vol. 1 No. 1 , pp. 5-14.

Kuipers, E.H.C., Desportes, I. and Hordijk, M. (2019), "Of locals and insiders - a "localized" Humanitarian response to the 2017 Mudslide in Mocoa, Colombia?", Disaster Prevention and Management: An International Journal, Vol. 29 No. 3, pp. 352-364.

Lewin, R., Besiou, M., Lamarche, J.-B., Cahill, S. and Guerrero-Garcia, S. (2018), "Delivering in a moving world looking to our supply chains to meet the increasing scale, cost and complexity of humanitarian needs", Journal of Humanitarian Logistics and Supply Chain Management, Vol. 8 No. 4, pp. 518-532.

L'Hermitte, C., Tatham, P., Bowles, M. and Brooks, B. (2016), "Developing organisational capabilities to support agility in humanitarian logistics: an exploratory study", Journal of Humanitarian Logistics and Supply Chain Management, Vol. 6 No. 1, pp. 72-99.

Majewski, B., Boulet-Desbareau, P., Slezak, M., Meulder, F.D. and Wilson, K. (2012), Joint Evaluation of the Global Logistics Cluster, available at: https://www.wfp.org/content/joint-global-logisticscluster-evaluation-terms-reference (accessed 11 May 2010).

Medel, K., Kousar, R. and Masood, T. (2020), "A collaboration-resilience framework for disaster management supply networks: a case study of the Philippines", Journal of Humanitarian Logistics and Supply Chain Management, Vol. 10 No. 4, pp. 509-553.

Mutebi, H., Ntayi, J.M., Muhwezi, M. and Munene, J.C.K. (2020), "Self-organisation, adaptability, organisational networks and inter-organisational coordination: empirical evidence from humanitarian organisations in Uganda”, Journal of Humanitarian Logistics and Supply Chain Management, Vol. 10 No. 4, pp. 447-483.

OCHA (2007), Appeal for Building Global Humanitarian Response Capacity, Office for the Coordination of Humanitarian Affairs, New York, NY, available at: https://reliefweb.int/report/world/appealbuilding-global-humanitarian-response-capacity (accessed 1 June 2021).

Steets, J., Grünewald, F., Binder, A., Geoffroy, V.D., Kauffman, D., Krüger, S., Meier, C. and Sokpoh, B. (2010), Cluster Approach Evaluation 2 Synthesis Report, available at: https://www. humanitarianresponse.info/system/files/documents/files/Cluster\%20Approach\%20Evaluation \%202.pdf (accessed 11 May 2010).

Stoddard, D.A., Harmer, A., Haver, K., Salomons, D.D. and Wheeler, V. (2007), Cluster Approach Evaluation Final, OCHA Evaluation and Studies Section (ESS), available at: www. humanitarianreform.org/Default.aspx?tabid $1 / 4457$.

Veatch, M. and Goentzel, J. (2018), "Feeding the bottleneck: airport congestion during relief operations", Journal of Humanitarian Logistics and Supply Chain Management, Vol. 8 No. 4, pp. 430-446.

Vega, D. and Roussat, C. (2015), "Humanitarian logistics: the role of logistics service providers", International Journal of Physical Distribution and Logistics Management, Vol. 45 No. 4, pp. 352-375.

Wood, E.X. and Frazier, T. (2020), "Decentralized humanitarian aid deployment: reimagining the delivery of aid", Journal of Humanitarian Logistics and Supply Chain Management, Vol. 10 No. 1, pp. 1-20.

\section{Corresponding author}

Leif-Magnus Jensen can be contacted at: leif-magnus.jensen@ju.se 


\section{Appendix}

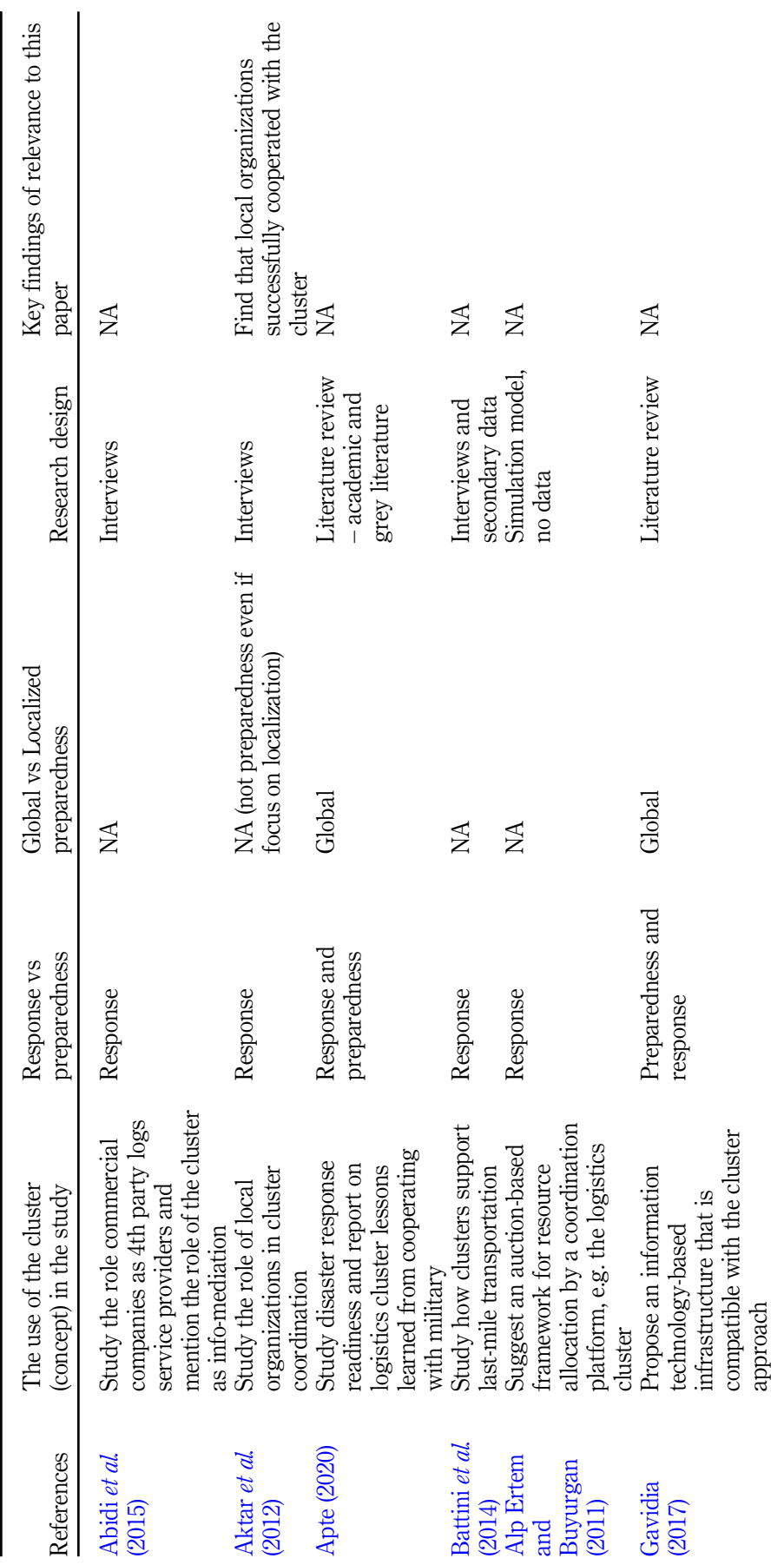

Coordination at the 10-year mark

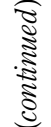

Table A1. Cluster research in JHLSCM 2010-2021 


\section{JHLSCM}

11,4

598

Table A1.

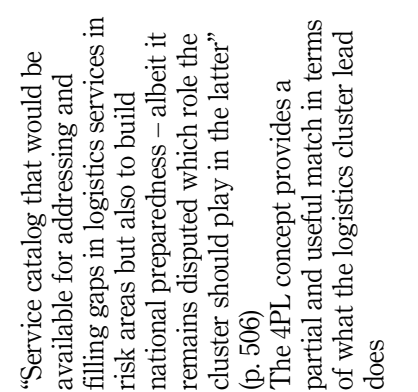

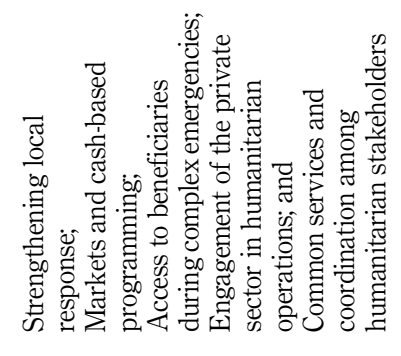

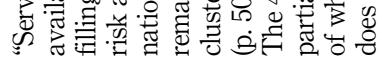

ล ส ส

(1)
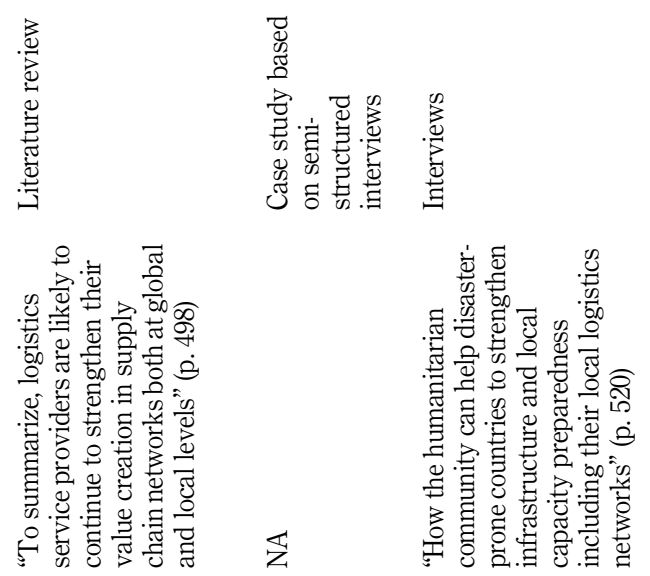

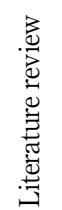

惫

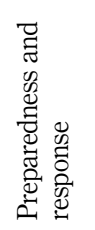

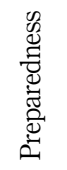

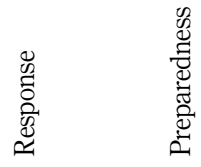

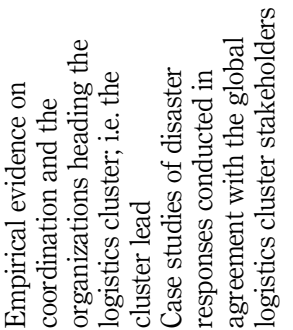

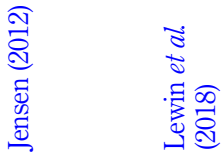

